\title{
What Kind of Society is MRS, Anyway?
}

Wrapping up my year as MRS President, I find myself with an odd feeling. I enjoyed the year very much. I interacted with far more MRS members than in the 20 years I have been a member, and the MRS staff is like family to me now. I was able to partake in many aspects of our profession that would not otherwise be part of my day job, such as lobbying for materials science in Washington. The odd part is that I am conflicted about the role and identity of MRS. Perhaps this is the inevitable result of addressing those issues for a year. I spoke to many other members, and I know some of them have strong feelings as well. Other societies, I am told, are grappling with the same issues.

What is the nature of MRS? I suspect being a member of the Materials Research Society is not the same as being a member of the American Physical Society (APS) or the American Chemical Society, for example. About half of our members view MRS as their second home; they vacation with us for the meetings, but don't join if they attend neither the Spring nor Fall meeting. Many of us have a primary professional residence elsewhere. Societies representing pure disciplines may enjoy more member loyalty than we do. A physicist must belong to APS to be part of the physics community, and is therefore likely to be a permanent member of APS; it is her conduit to the physics world. However, a materials scientist (many of whom are not formally trained in the field, but rather possess, for example, EE or chemistry degrees) needn't be a permanent member

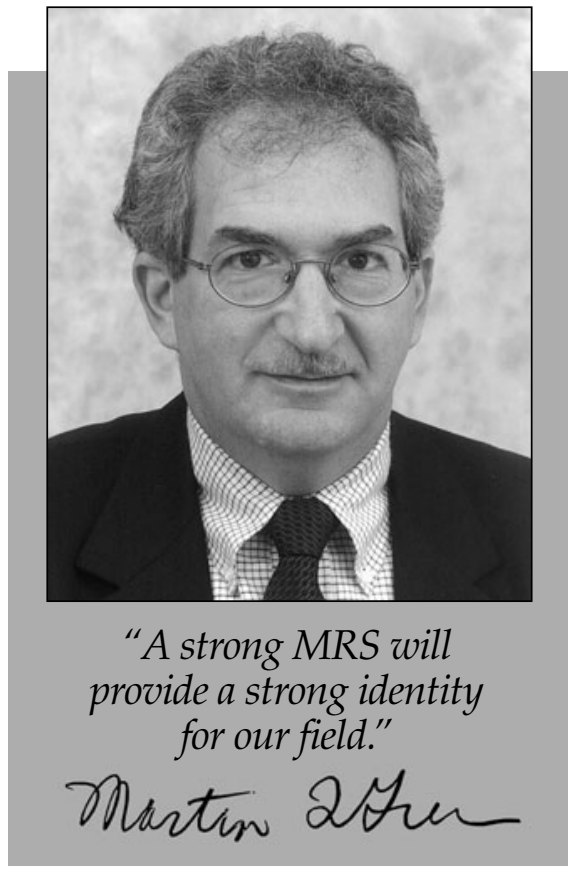

of MRS. This is partly because we allow him to become an MRS member just by attending one MRS meeting a year. But also, perhaps the MRS doesn't offer her much beyond the meetings and the MRS Bulletin, to merit her permanent commitment. To many of our members, MRS is relevant only once or twice a year.

MRS has evolved significantly since its inception in 1973. I'd like to share two MRS membership trends that jump off the page at me. Figure 1 shows a breakdown of MRS membership with respect to workplace, over time. Since 1988, industrial membership has been flat and then slightly declining, whereas academic membership has increased. Student and government memberships have slightly increased. Thus, total MRS membership has increased, but almost entirely due to academics. Figure 2 shows similar trends with respect to U.S.- and non-U.S.-based members. Since 1990, U.S. membership has been absolutely flat, whereas non-U.S.based membership has increased steadily. Combining Figures 1 and 2, one comes to the conclusion that all MRS growth since 1990 can be attributed to non-U.S.-based academics. Given that the United States just enjoyed a decade of unprecedented economic growth, largely driven by our high technology expertise, this is an astounding conclusion. Although it is a tribute to the globalization of science, it also suggests that the MRS has been largely irrelevant to the techno-economic miracle of the 1990s (although it undoubtedly played a huge role in nurturing the underlying technologies).

Sometimes I think of materials scientists as the mutts* of the physical science world. After all, our field is a mélange of science (e.g., physics, chemistry, crystallography)

* A mutt is a mixed as opposed to a pure bred (pedigreed) dog. Don't take my analogy in the wrong way. I own an adorable mutt, and she's everything I've ever wanted in a dog. Mutts are the best dogs because they are generally healthier and in possession of more "dog sense" than pure breeds. Also, they are usually free.

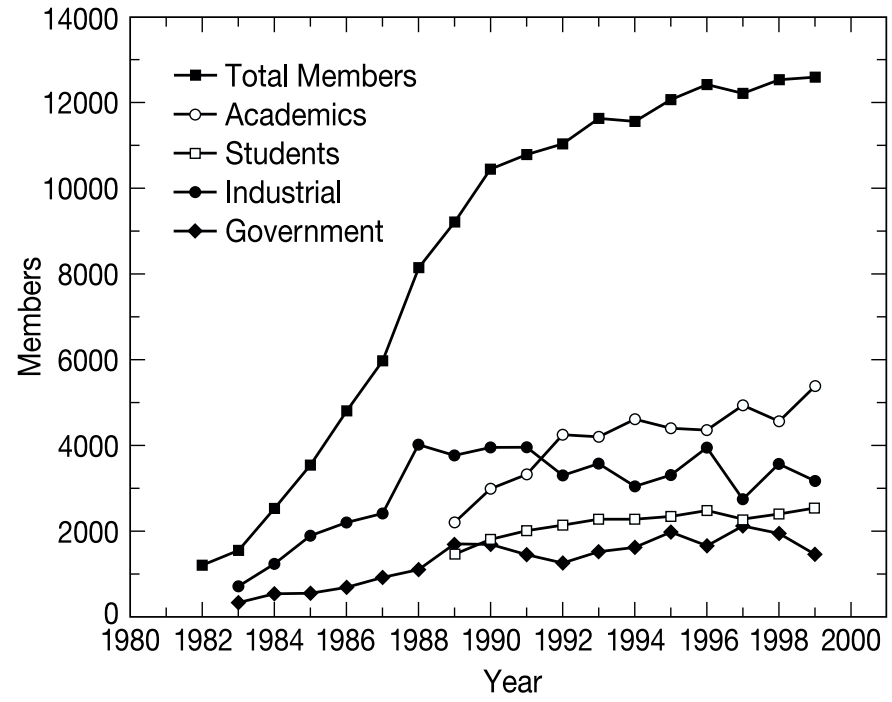

Figure 1. MRS membership, by workplace, over time.

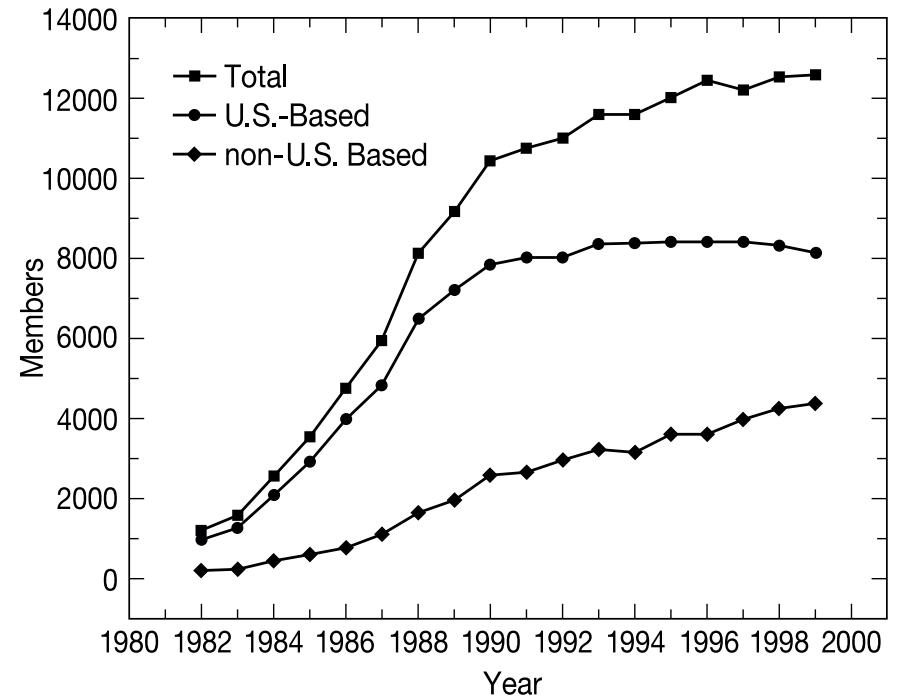

Figure 2. MRS U.S.- and non-U.S.-based membership, over time. 
and engineering (chemical, electrical, mechanical). Its existence at the intersection of many pure disciplines (see what I mean about mutts?) is what attracted us to the field in the first place. However, I'd like to point out that the very nature of our field has repercussions for its survival. Our community has been very successful in integrating whole chunks, for example, thermodynamics, kinetics, plasticity theory, bandgap theory, and so on, of pure disciplines into "materials science." This seamless integration may be responsible for some loss of identity in the materials field: Since the science of thermodynamics is common to all materials, one no longer need distinguish between metallurgy, ceramics, solid-state materials, and polymers. By making them all occupy the same "materials science" tent, their individual identities have been compromised. I'm told there is virtually no funding for basic research in metallurgy these days. Materials science, yes, but metallurgy, no. Hopefully, "materials science" will not be a victim of its own success. New fields, such as nanotechnology and molecular self-assembly, may be seen as more physics and chemistry/biology than materials science, respectively. We must be careful. At this time, materials science has no profile in secondary schools; students find out about our field much later on in their academic careers. The public in general is clueless about our field until properly prompted.

I hope for sweeping changes within MRS in the next few years. I'd like to see this mission for MRS: Through the quality of our meetings, publications, and Web site, we must make our Society the permanent home for the materials scientist and engineer. I think MRS should grow to include programming for the great num- ber of industrially based materials practitioners that don't know about us. The " $\mathrm{R}$ " in MRS should stand for research, development, and manufacturing, not just research. If we don't move in this direction, we will be a society of academics by default. Don't we want all segments of the materials community represented at our meetings? Let's grow the materials pie by merging with other societies, if need be. A strong MRS will provide a strong identity for our field. If we lose our identity, our students and our funding will be backscattered to the departments that spawned our field. In fact, many smaller materials departments have already been absorbed by their neighbors.

Or, we can just continue to put on the world's most interesting materials science meetings, twice a year.

MARTIN L. GREEN 2001 MRS President

\title{
Coming 2002 MIRTS Uorkshop Series \\ International Workshop on Processing and Applications of Superconductors \\ August 1-2, $2002 \quad$ www.mrs.org/meetings/workshops \\ Park Vista Resort Hotel • Gatlinburg, Tennessee
}

\author{
Workshop Chair: \\ M. Parans Paranthaman, ORNL \\ Co-Organizers: \\ A. Goyal, ORNL \\ R. Feenstra, ORNL \\ Teruo Izumi, ISTEC-SRL \\ Venkat Selvamanickam, IGC-SuperPower, LLC
}

Information and Registration Details on the International Workshop on Processing and Applications of Superconductors contact:

\section{MRIS $\substack{\text { Materials } \\ \text { Research } \\ \text { Society }}^{\text {M }}$}

506 Keystone Drive, Warrendale, PA 15086

Tel: $724-779-3003$

Fax: 724-779-8313

E-mail: info@mrs.org

\section{Purpose and Description}

Major advances have been made in the last 14 years in high-temperature super-conductor (HTS) research, resulting in increasing use of HTS materials in commercial and precommercial applications. HTS conductors are expected to be useful for numerous electric power applications, including transmission cables, transformers, SMES, current limiters, motors, and generators, etc. High efficiency, high power density, and improved materials utilization are some of the benefits expected from HTS in this century. Much progress has made using BSCCO silver sheathed wire and tape on processing and applications. Research on the YBCO-based next-generation conductors is now intensively carried out in the world. The focus of this workshop will bring the discussions between the international experts toward the development of long-length YBCO-coated conductors and applications of high-temperature superconductors. 